\title{
A Practical Perspective on Resilience in Organizations: The Interplay Between Structure and Action
}

\author{
Anouck Adrot, Oriane Sitte de Longueval, \\ and Alexandre Largier
}

\section{INTRODUCTION}

In many sectors, organizational resilience represents a useful way to bounce back from incidents and promote activity continuity (Lovins \& Lovins, 1982, cited by Wildavsky, 1988). Accordingly, a large spectrum of tools, norms and standards-what we label here as 'frameworks'-has been produced and internationally appraised. However, frameworks do
A. Adrot (凶)
Paris-Dauphine University PSL, Paris, France
e-mail: anouck.adrot@dauphine.psl.eu
O. S. de Longueval
Université de Genève, Genève, Switzerland

\begin{abstract}
A. Largier
Institut de radioprotection et de sûreté nucléaire (IRSN), Paris, France e-mail: alexandre.largier@irsn.fr
\end{abstract}

(C) The Author(s) 2022

R. Pinheiro et al. (eds.), Towards Resilient Organizations and Societies, Public Sector Organizations, https://doi.org/10.1007/978-3-030-82072-5_5 
not always fit into organizational settings, and gaps can emerge between resilience frameworks on the one hand and resilience in action on the other. Moving away from strict rules does not necessarily result into a negative outcomes (Walls \& Hoffman, 2013). However, discrepancies between resilience frameworks and action can generate uncertainty. For instance, they can undermine overall confidence in an organization's ability to prepare for, detect and address events (Shrivastava, 1987).

As those insights suggest, there is a need to better understand how resilience frameworks and action relate to each other in practice. Previous research has highlighted their interplay through a literature review (Hale \& Borys, 2013) but has fallen short of providing details on the conditions under which such interplay shapes practice. In this chapter, we approach organizational resilience through the practice-based lens offered by Schatzki (1996). Approaching resilience as a practice allows us to focus on the interplay between action and structure. By doing so, we distinguish on the one hand structural aspects of resilience and, on the other, enacted resilience (that we approach as action). Based on such conceptualization, this chapter addresses the knowledge gap identified by with the following question: What is the nature of the interplay between structure and action that both comprise resilience as practice?

To properly investigate this question, our analysis is based on two empirical cases from two French organizations: a public administration in charge of coordinating resilience at a regional level (Fed), and a service in charge of Crisis Management Teams (CMTs) in a public transportation company (Ral). These two organizations developed knowledge intensive capabilities in order to frame, experiment and develop resilience. While they adopted radically different practical modalities in settling resilience capabilities, they experienced similar difficulties that we analyse in this chapter.

Our findings detail the interplay between structure and action that both comprise resilience as practice. More specifically, our findings outline how, at the initial steps of an organization's framing of resilience, general and practical understanding can shape action while coming at odds with the organization's teleo-affective structure. By drawing on practice theory, the chapter opens the black box of resilience as a practice. Our findings inform discussion on three major points: (i) resilience, as a practice is evolutionary and complex; (ii) organizations need to fully 
consider resilience's teleo-affective structures before designing organizational resilience; and (iii) proponents of resilience and their agency are essential.

\section{Organizational Resilience and Practice}

For two decades, the notion of resilience has gained momentum (Manyena, 2006). Increasing attention from authorities, the public and organizations towards the concept stems from growing likelihood of unexpected but highly destructive events. Resilience can be defined as 'the ability of an entity, individuals, community, or system to return to normal condition or functioning after the occurrence of an event that disturbs its state' (Wiig \& Fahlbruch, 2019, p. 1).

Organizations are particularly vulnerable because a large spectrum of events can disrupt their activities and significantly impact their functioning without notice. Organizational environments have also grown complex: threats of a diverse nature now impact each other and organizations have progressively become vulnerable (Perrow, 2006). This has strong implications for organizations' awareness of their inner vulnerabilities, threats and the need to develop organizational capabilities to handle them.

In this context, organizational resilience was defined as ' $a$ deliberate effort to become better able to cope with surprise' (Lovins \& Lovins, 1982, cited by Wildavsky, 1988). This effort corresponds 'to the maintenance of positive adjustments under challenging conditions such that the organization emerges from these conditions strengthened and more resourceful' (Vogus \& Sutcliffe, 2007, p. 3418). Because the characteristics of disasters are changing and bringing unforeseen events (Djalante \& Lassa, 2019), a practical adaptation of resilience frameworks by organizations is of paramount importance. While the absence of any framework can be a major impediment to the implementation of resilient practices, an overly tight normative framework can prevent the emergence of resilience.

In line with this view, the two definitions provided here both uncover the practical dimension of resilience. Practices correspond to 'an organized, open-ended, spatial-temporal manifold of actions' (Lindberg \& Rantatalo, 2015, p. 564). Practices are not easy to conceptualize, even though they contribute to the fabric of organizations as well as their transformation (Schatzki et al., 2001).

In line with this view, the definition of organizational resilience provided above highlights how resilience involves 'efforts', indicating 
continuous intentional, behavioural and emotional involvement of individuals and groups of individuals who work for the organization (we refer to them in this chapter through the term 'agent'). Resilience is therefore not understood as the mechanistic implementation of formal rules but, rather, as a manifold of actions undertaken by agents. These actions might remain untracked or uncontrolled and correspond to some sort of organizational slack necessary for organizational reliability (Schulman, 1993). The latter definition outlines the transformative dimension of resilience and suggests that, in order to become resilient, organizations shape their own activities. This transformation targets the development of both proactive and reactive capabilities, respectively, designed to bounce forward or bounce back events (Pettersen \& Schulman, 2019). Hence organizational resilience as practice fully participates in the development of crucial capabilities, yet still remains challenging to grapple with empirically.

In our view, considering the practical dimension of resilience helps address the challenge of how best to approach the situatedness of resilience. But what is resilience as practice? Both scholars and practitioners lack knowledge of the practical achievement of organizational resilience (Boin \& Van Eeten, 2013; Duit, 2016). Addressing this need, we detail in the coming section our rationale for drawing on Schatzki's view of practice. We then detail this perspective as applied to the question of resilience, and outline the remaining question regarding the nature of the interplay between resilience structure, on the one side, and resilience action on the other side.

\section{Schatzki's Approach to Practices}

This chapter argues for Schatzki's conceptualization of practices as a valuable lens to better understand the dynamics underlying resilience. The practice view of organizations, as offered by Schatzki (2006), posits that organizational essence lies in its activities. Practice results from the interplay between its two major components, namely action and structure, which are both essential to any organizational activity. Figure 5.1 represents the mutual ties between action and structure. On the one hand, action, which describes what people concretely achieve (for instance running, filling a form or using equipment), represents the most straightforward expression of practice. On the other hand, the structure of practice corresponds to collective understanding and meaning of what 
Resilience as practice

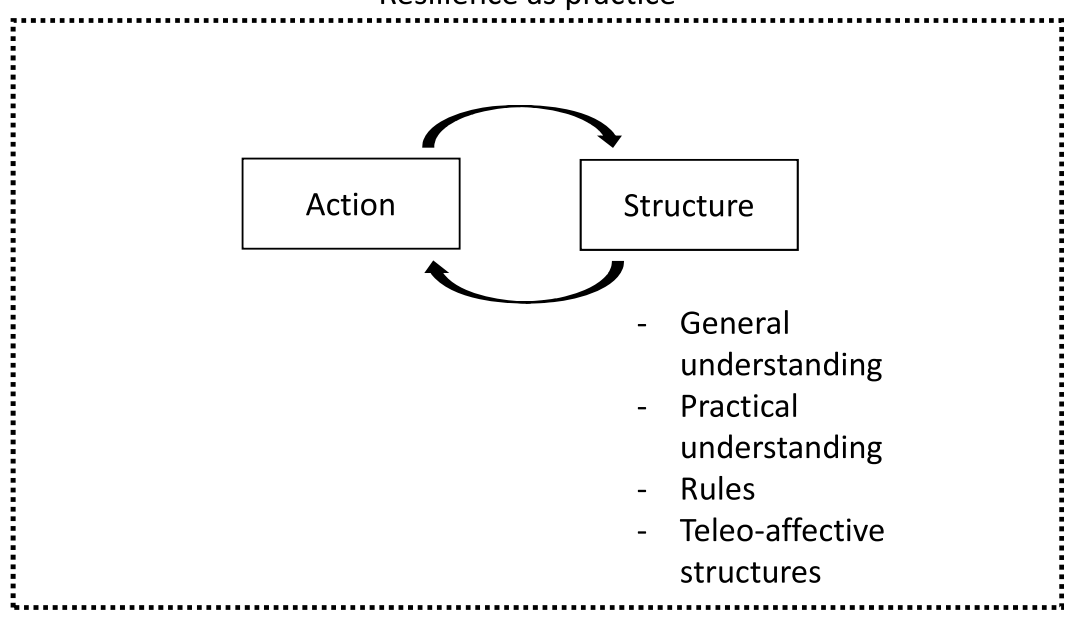

Fig. 5.1 Resilience as a practice: social arrangements between actions and structure, inspired from Schatzki (2002)

is correct or acceptable (Lindberg \& Rantatalo, 2015). Practice intelligibility stems from structures, which organise and regulate action. Reciprocally, action contributes to the delineation of practice structure. In other words, practices emerge from the influence of structures on action, and vice versa.

We now consider more thoroughly the major elements that comprise the structure of resilience as practice. In Schatzki's terms, practices are made of four major components: (1) Practical understanding corresponds to the practical knowing of what to do in a specific situation. For instance, practical understanding could be knowing which forms to use in a bureaucratic process or even how to send an email. According to Schatzki, the practical understanding corresponds to the knowledge of how 'to carry out desired actions through basic doings and sayings' (2012, p.16). This type of knowledge relies on practical rather than dialogical intelligibility. From this perspective, practical understanding embeds in action rather than being driven by formal rules or reasoning. (2) Rules correspond to the 'explicit directives, admonishments or instructions that participants in the practice observe or disregard' (Schatzki, 1996, p. 1864). Rules play an essential role in the continuity and intelligibility of practices. However, 
actors can also bypass rules, which means that social action can diverge from explicit norms and standards. (3) Teleo-affective structures include a large spectrum of emotions, beliefs and rituals that direct action and belong to the practice rather than the actors. Actors are not totally aware of the emotional, affective and teleological dimension of practice. (4) General understanding corresponds to the shared belief between actors involved in a practice.

The adoption of a practice-based view of resilience leads to an important point: resilience evolves through an interplay between structure on the one hand, and action on the other. Social and material arrangements bridge (Schatzki, 2002; Suchman, 2007) concrete actions undertaken by practitioners and the structures that govern these actions (including norms, rules, protocols, directions from hierarchy, strategic objectives and methodologies). Approaching organizational resilience through Schatzki's lens provides two major sources of insights on resilience. First, it suggests resilience is part of the social fabric of the organization rather than a spontaneous reaction to events. Second, it draws attention to the numerous and invisible ties between structure and action.

\section{Resilience Structure and Action Interplay}

Apparent examples of the gap between resilience structure and action abound in the literature. For instance, in the case of the Bhopal disaster, Union Carbide hardly considered experts' recommendations regarding its daily routine, thereby undermining its capability to deal with the explosion of its factory in December 1984 (Shrivastava, 1987). As another example, the 2012 Concordia accident resulted from a clear departure of the ship's captain from formal frameworks. These two examples echo Schatzki's view on the importance of the interplay between resilience structure and action. This interplay, stemming from social arrangements, is not always contradictory and might be more complex.

In organizations, informal social arrangements-those primarily concerning humans, artefacts and things (Schatzki, 2002)—can occur in relation to a spectrum of topics (Benson, 1977). In situations requiring resilience capabilities, social arrangements may concern the distribution of tasks or the nature of emergency practices (Adrot \& Garreau, 2010). So far, social arrangements related to resilience have mostly been observed in situations where organizations need to address specific incidents. 
They have been less frequently considered in relation to the development of resilience capabilities. From existing research on this topic, we learnt that social arrangements between structure and action related to resilience play an important role in organizational functioning and represent an important source of human agency (Reynaud, 1989). In line with this view, agents need to articulate highly structured frameworks to emerging patterns of action (Moynihan, 2012). This means that, well before incidents, organizations ought to overcome a seemingly dichotomous relation between resilience structure and action (Boin \& Van Eeten, 2013). To do so, they need to know more about the nature of the interplay between structure and action, which has remained partially unexplored so far, In order to address this gap, this chapter proposes examining two empirical case studies.

\section{CAse Studies}

This chapter takes a comparative approach to two distinct cases. Because of constraints around anonymity, we label these two organizational entities Ral and Fed. Both Ral and Fed are part of larger organizations that faced unexpected events. In addition, they were both involved in the development of resilience capabilities. However, Ral and Fed abided by divergent resilience frameworks. Ral developed an expert-oriented view of resilience by creating a service dedicated to the management of crisis management teams (CMTs). By contrast, Fed made the choice of approaching as transverse matter by developing collaborative and transverse capabilities. We provide in the remainder of this section additional detail on each case under investigation.

Ral manages crisis management teams (CMTs) and was created by a formerly public organization specialized in railway transportation. In recent years, the growing density of urban spaces and cities has resulted in the French population increasingly relying on railway transportation for daily needs. In addition to that, the railway infrastructure has benefited from major technological advances. This has made trains one of the safest modes of transport in Europe. In the busiest regions, even minor traffic events - such as an electricity blackout, heavy rains or even high temperatures - can lead to the cancellation of one or several trains, leaving sometimes hundreds of people waiting in the station. In such conditions, stations located in the busiest regions of France can be overwhelmed with users. In the wake of a dramatic blackout that resulted in physical 
violence in a rail station, the organization decided to formulate a strategy for resilience. A project was launched to build internal expertise. In line with this vision, Ral was created, comprising teams of experts in charge of managing critical situations. Thanks to these experts, the organization increased its capability to manage a safer and also more efficient system of mass evacuation in case of incidents. When our investigation was taking place, Ral was composed of 88 employees, half of them coming from safety professions and the other half from sales professions. They could be mobilized 365 days a year and $24 \mathrm{~h}$ a day. Their deployment was ordered by a national Operating Manager during the occurrence of an unexpected incident. When Ral is triggered, its members physically go to the incident site. There, their mission is double: sales agents provide guidance to travellers and, if necessary, water and food. Safety agents provide security through their armed presence and respond to any disruptive behaviour.

Fed is a public organization in charge of resilience and crisis coordination in one of the busiest regions in France. Its mission is legally defined at a regional level and targets civil safety, continuity of economic activity and social well-being in the case of disrupting events such as terrorist attacks, extreme weather and even flooding. According to French legal frameworks, management of local events falls under the responsibility of a mayor (in cases where a municipality is involved) or a prefect (in cases where the event involves multiple municipalities). However, some events could require additional equipment to those locally available and involve regional decision-making. This is where Fed intervenes. In such cases, its mission is to orchestrate the supply of necessary equipment to alleviate the economic and social costs associated with an incident. Fed is also in charge of gathering and transmitting information to regional decision-makers in a timely fashion, as well as liaison between organizations involved in the response to an incident. When our investigation was taking place, Fed was comprised of approximately 80 employees who had each developed through the years strong but specific expertise on resilience. For many decades, Fed had favoured siloed expertise, mostly based on specific hazards, such as floods, chemical risks, etc. Some years ago, though, Fed initiated an organizational transformation project, taking the opportunity to renew its own vision of resilience. Fed's new vision consisted of approaching incidents from a holistic and transversal stance, which had two implications: (i) implementation of transversal management of resilience across Fed services (which meant that not only one but all Fed services were in charge of handling a specific incident); and (ii) 
development of situational awareness within the organization. Situational awareness allows the anticipation of the cascading effects of one specific event. It can be illustrated by this short example: a flood can block deliveries and access to commercial activities, thereby significantly endangering economic activity at a regional level. While Fed was in charge of handling the cascading effects of events such as floods, it still lacked situational awareness and collaboration across services before its transformation. This resulted in Fed's decision to develop dialogue between its various but complementary sources of expertise. This combined with Fed's willingness to diffuse its new vision of resilience and reorganize its processes, based on the idea that resilience is an important matter for everyone and requires all services' expertise and contribution. For this reason, Fed aimed at overcoming existing expertise silos. Table 5.1 summarizes the specifics of functioning emerging from Ral and Fed's organizational contexts. $^{1}$

Multiple reasons accounted for our decision to compare Ral and Fed. First, both organizations shared contextual and structural commonalities, which allowed us to focus on the differences between their practice of resilience. In addition to similar size and public nature, they both represent organizations whose resilience can significantly impact the economic activity of a European region. Moreover, they both elaborated innovative visions of resilience in the aftermath of a disruptive event. By innovative, we mean that they investigated resilience standards and best practices, in particular by exploring state of the art. Both organizations framed their own strategy based on shared representation of what resilience should be. Fully aware of the need to adapt organizational structures in order to implement a resilience strategy, both Ral and Fed were involved in projects that resulted in new organizational settings. They both undertook the implementation of an innovative vision of resilience, thereby designing new processes, activities and task distribution. For instance, Ral initiated reflection on the impact of a transportation blackout on wellbeing in dense urban areas (as well as the economic impact of people's inability to attend their workplace). In a similar way, Fed thoroughly examined its responsibility in emergency coordination and collaborated

${ }^{1}$ Please note that the dimensions of the case studies depicted here correspond to the main characteristics of organizations investigated in this volume. Additional detail relating to the transformative dimension of resilience, and public nature of organizations in the introduction and other chapters of this volume. 
Table 5.1 Commonalities and differences between Ral and Fed

\begin{tabular}{|c|c|c|}
\hline & Ral & Fed \\
\hline Sector & Transportation & Civil safety \\
\hline Publicness & $\begin{array}{l}\text { The state is one of Ral's major } \\
\text { stakeholders. Ral is in charge } \\
\text { of managing transportation } \\
\text { activities and infrastructures as } \\
\text { a common good }\end{array}$ & $\begin{array}{l}\text { Public organization. In } \\
\text { charge of economic } \\
\text { resilience and coordination } \\
\text { between public and private } \\
\text { organizations to support } \\
\text { regional response to events }\end{array}$ \\
\hline Response to incident & $\begin{array}{l}\text { Consists of supporting the } \\
\text { continuity of transportation } \\
\text { activities and managing } \\
\text { passengers' flow and evacuation } \\
\text { through the transportation } \\
\text { network }\end{array}$ & $\begin{array}{l}\text { Support to overall regional } \\
\text { activity continuity and civil } \\
\text { safety }\end{array}$ \\
\hline $\begin{array}{l}\text { Trigger for search for } \\
\text { resilience }\end{array}$ & $\begin{array}{l}\text { Major incident in a station that } \\
\text { impacted both users, personnel } \\
\text { and transportation flows }\end{array}$ & $\begin{array}{l}\text { Organizational diagnosis } \\
\text { and search for productivity } \\
\text { and relevance }\end{array}$ \\
\hline \multirow[t]{2}{*}{ Resilience framework } & Siloed & Transverse \\
\hline & Expert-oriented & $\begin{array}{l}\text { Every member of Fed } \\
\text { contributes to its } \\
\text { resilience, in particular } \\
\text { through situational } \\
\text { awareness and } \\
\text { occupational agility }\end{array}$ \\
\hline Resilience drivers & $\begin{array}{l}\text { Creation of Ral and Crisis } \\
\text { Management } \\
\text { Teams-CMTs-dedicated to } \\
\text { resilience and developing the } \\
\text { capabilities needed to be } \\
\text { resilient }\end{array}$ & $\begin{array}{l}\text { Redefinition of } \\
\text { organigrams, task } \\
\text { distribution, diffusion of a } \\
\text { crisis-prone culture in a } \\
\text { transversal fashion }\end{array}$ \\
\hline
\end{tabular}

with researchers to reflect on its need to better perform its mission. Another similarity lies in their enthusiasm with respect to their chosen path for resilience.

\section{Data Collection AND Analysis}

The authors collected data at Ral and Fed from 2015 to 2018. Observing Ral and Fed in routine, emergency and critical situations helped triangulate data, including interviewees' claims about their emotions as compared with their actual experience on the field. For instance, an interviewee once claimed 'craving for opening one's heart to the team' when meeting one of 
Table 5.2 Data collection

\begin{tabular}{|c|c|c|}
\hline Data source & Ral & Fed \\
\hline Interviews & 10 & 10 \\
\hline Observation & $\begin{array}{l}\text { Team observation }>30 \mathrm{~h} \text {. The } \\
\text { CMTs' activities as well as their } \\
\text { interactions were observed in the } \\
\text { train stations through } 6 \mathrm{~h} \\
\text { observation sessions }\end{array}$ & $\begin{array}{l}\text { Crisis cells }>40 \mathrm{~h} \text { (in routine, } \\
\text { exercises, large-scale emergencies } \\
\text { and critical settings) }\end{array}$ \\
\hline Archives & $\begin{array}{l}\text { Internal and external archive related } \\
\text { to Ral's history. Existing research } \\
\text { on Ral and railway management }\end{array}$ & $\begin{array}{l}\text { Internal archive including } \\
\text { returns on experience and } \\
\text { transformation project }\end{array}$ \\
\hline
\end{tabular}

the authors for the first time. The observation of the interviewee's actual practices and interactions with their subordinates (including the team) helped refine the meaning of such a claim. Finally, archives have played an important role in us better understanding the cultural legacy, events (particularly past critical situations) and past interactions that shaped the teleo-affective structure of Ral and Fed. Table 5.2 represents data collection.

The analysis was completed in an iterative and dialogical fashion. By iterative, we mean that the authors met on a regular basis from the start of the project. By dialogical we mean that the findings were regularly discussed between the authors, which supported the refinement of the initial analysis.

\section{FINDINGS}

Based on Schatzki's thinking, the findings uncover the nature of the interplay between the structure and action that composes resilience as a practice. To ensure the clarity of our findings, this section is divided into four parts that examine the interplay between resilience action and structures, namely: (i) practical understanding; (ii) general understanding; (iii) rules; and (iv) teleo-affective structures. In each subsection, we focus our analysis on the ties between the ongoing flow of resilience action and one of the components of the structure of resilience practice. Figure 5.2 represents how resilience practice structure and resilience practice action were connected in Ral and Fed. 


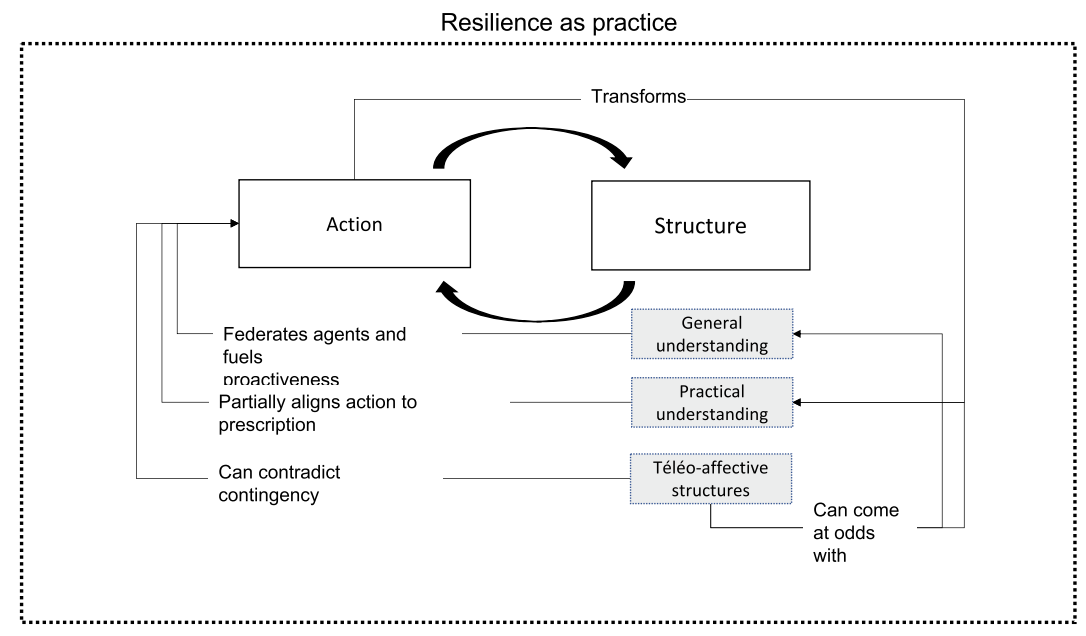

Fig. 5.2 Resilience as practice in Ral and Fed: interplay between structure and actions (inspired from Schatzki, 2002)

\section{General Understanding}

As a reminder, general understanding corresponds to the shared belief between actors involved in a practice. Both Ral and Fed presented a general understanding of the ideal of resilience as framed by its proponents. We demonstrate in the following paragraphs how that general understanding united actors, bolstering motivation and fueling initiatives to develop resilience capabilities. Consequently, resilience action was significantly inspired by general understanding.

Rather than developing its general understanding of resilience from scratch, Ral based it on existing examples and knowledge. Drawing on well-known cases of resilience and high reliability organizations (HROs), Ral framed resilience as a specific source of expertise and collaborative skills. From this perspective, the founders of the CMTs promoted expert leadership and encouraged CMTs to act as experts, and rely on selfevaluation and collegial agreement on objectives. At the same time, the creation of the CMTs provided to their members a sense of empowerment consistent with a general understanding of resilience in HROs. The CMT members also developed strong affective ties among each other. These ties, in addition to fostering a strong sense of belonging within 
the service, contributed to uniting the CMT members in a shared view of resilience as essentially collaborative. This supported CMT innovation and improvement of their processes.

Based on organizational diagnosis, Fed developed a general understanding that resilience was a collective capacity, resulting from decentralized distribution of responsibilities and agile coordination. According to this view, proponents of resilience in Fed argued that it had to develop its ability to orchestrate expertise, share information and collaborate, not only within Fed but also with Fed's partners. Fed's proponents had a strong motivation for diffusing this general understanding of resilience among its stakeholders and partners. From this perspective, Fed's general understanding was a strong driver to resilience action. For instance, Fed applied successfully for a grant to fund a large-scale crisis simulation exercise that would involve more than one hundred organizations, as well as the majority of its internal services. Fed invited hundreds of practitioners to participate and massively communicated on its general understanding of resilience. This action contributed to strengthening a shared understanding of resilience as a transverse matter and had a powerful effect on action. In particular, multiple unexpected and exogenous events in the same year (including terrorist attacks, critical resources shortages and floods) compelled Fed's members to cope with major stress and encouraged collective reflexivity about their practices in Fed. Fed's members hoped to act in accordance with Fed's general understanding of resilience. When they could not do so, they experienced significant frustration. This illustrates how the newly generated general understanding of resilience influenced action.

\section{Practical Understanding}

Practical understanding corresponds to the practical knowledge of what to do in a specific situation. At the initial stages of organizational transformation towards resilience, Ral and Fed managed to promote a practical understanding of resilience that aligned with the general understanding framed and supported by the resilience proponents. The practical understanding developed and supported consistency between general understanding on the one hand and action on the other. However, the alignment between actions and practical understanding eventually faded because of two major factors. First, the contingency of actions in certain events prevented agents' abiding by the practical understanding. Second, 
ongoing action reframed practical understanding. These factors resulted in progressive questioning of Ral and Fed's general understanding of resilience.

Consistent with the general understanding of resilience, the Ral's CMTs increased their ability to handle specific missions related to resilience, which very few other agents could achieve. For instance, they developed processes and know-how for mass evacuation and management of large numbers stuck on a platform (such as when a train is cancelled). They became knowledgeable of train stations to the point where they always kept in mind which train they could rely on to evacuate a specific place at a specific time. They elaborated several techniques to deal with stressed clients and cool down tense situations involving frustrated customers. Finally, the CMTs developed their own skills in order to avoid any member of the team being assaulted or hurt by a customer (which had happened to train station managers in critical situations). This practical understanding of resilience shaped action as the CMT members began to use them intuitively. The CMTs designed such techniques and know-how across the occupational profiles of their team. For instance, the CMT members in charge of customer relationship management learnt basic elements of safety. They were aware that safety is not their source of expertise and frequently made sure that they were not alone when interacting with a customer. By doing so, they enacted and reinforced an expert-oriented vision of resilience. However, the diffusion of resilience practical understanding across services eventually contradicted Ral's initial vision of resilience as strictly driven by experts. Ral acknowledged the importance of train station managers inspiring and learning from the source of expertise as constituted by the CMTs. The image of the CMTs as highly reliable and robust teams also encouraged Ral's members with respect to resilience. While Ral's vision of resilience focused on experts, it tended to become more transversal as other teams were inspired by CMT practices.

In Fed, general understanding promoted the development of practical understanding. Practical understanding concerned good practices to anticipate economic, social and ethical dilemmas that an incident such as a hydrocarbon shortage could bring about for the authorities in an economically productive region. By making the effort to draw a systemic overview of the effect of a hydrocarbon shortage on the economy, Fed's agents managed to identify and alert partners that they needed to involve in a response in a timely manner. This practical understanding aligned with 
the general understanding of resilience as a shared responsibility. Accordingly, Fed developed experience and a certain level of mastery in the management of information transmission as well as the command chain that would result if the region was impacted. It developed information platforms and technologies that aimed at easing information transmission within Fed and between Fed and its partners. The implementation of these technologies resulted in the adoption of new protocols among Fed's partners that were tested in large-scale exercises and used during incidents.

From this perspective, the development of Fed's practical understanding of resilience significantly shaped resilience action. Fed's practical understanding was not only formal but also had an informal dimension. Consistent with the general understanding that resilience relies on coordination between proactive organizations and individuals, Fed's agents spent part of their worktime in crisis cells, clarifying incorrect information that was transmitted through the command chain. This supported transverse coordination. In addition, they developed informal social networks and collaborative ties with other organizations to promote effective transmission of information. By doing so, Fed developed informal social bonds and connectiveness (as defined by Putnam, 2000) as a source of reliance for resilience. This aspect was hardly formally stated by interviewees, but frequently observed in crisis cells. Finally, the practical understanding of resilience also involved curiosity, in particular towards alternate modes of information transmission such as social media. Hence, practical understanding had a framing effect (as approached by WongParodi et al., 2015) on resilience action. However, in extreme situations (such as terrorist attacks), Fed also confronted information retention from partners, which meant that Fed had to deal with partners who radically departed from its practical and general understanding of resilience. In addition, emerging resilience action could contradict Fed's practical understanding. For instance, during some incidents, some Fed partners were not able to implement the protocols associated with the use of the platforms devoted to transversal coordination, and they failed to provide information. Because of the lack of information, Fed agents could not support clarification and orchestration of resilience. This reduced the ability of Fed agents to abide by their practical understanding of resilience. In the mid-term, this impeded Fed agents' confidence in resilience practical understanding and led them to feel less concerned by the need for transverse coordination or indirectly to promote siloed coordination. 


\section{Rules}

In both organizations, the framing and application of the rules related to resilience relied on support from proponents of resilience. However, they were at odds with the contingency of actions (including ad hoc action and others' action), which generated frustration among agents.

In Ral, rules related to resilience were initially designed by the team itself, in a collegial fashion. This mindset (as well as the framing of rules that resulted from it) was in line with Ral's general understanding of resilience as a matter of experts. These rules were institutionalized in the CMTs and had a strong impact on cohesion within and between the CMTs. These rules also fostered motivation and a sense of empowerment within the teams. However, it faded when the founders and initial leaders of the CMTs were replaced by managers who came from other services and had not experienced the creation of the CMTs as an embodiment of Ral's vision of resilience. This eventually generated tensions between Ral and other services. For instance, Ral had defined the conditions under which the CMTs were triggered and would take an active role in an incident. However, these rules did not align with the protocols released and implemented in railway national crisis centres.

Fed's general understanding of resilience as a transversal concern implied that the rules dictating resilience action were predefined at a minimum level. According to this view, each partner had to determine its own internal rules and would refer to the framework proposed by Fed for coordination. This vision was based on the metaphor of an orchestra, where every agent masters its own course of action so well that the hierarchy only gives a hint of what needs to be achieved so as to support coordination. As a result, the rules regarding resilience were defined at their minimum in order to give room to each coordinating organization to develop its own additional rules. However, some partners' rules were not precisely defined enough to make Fed's rules applicable. For instance, in the aftermath of the flooding of an urban area, Fed's agents were asked by health care partners to determine which entity was responsible for evaluating whether hospitals could be reused or not. While Fed's rules stated that each partner was in charge of handling its own assets, hospitals, at that time, did not benefit from rules to cover this peculiar circumstance. Facing such divergence between Fed and its partners' rules engendered frustration among agents. 


\section{Teleo-Affective Structure}

Teleo-affectivity represents a particular component of practice structure. While a teleo-affective structure has a strong experiential dimension (driven by emotions and intentions that can emerge on the spur of the moment), it is also grounded in culture, history and the legacy of organizations. This section explains how the newly created general and practical understandings of resilience came to be at odds with teleo-affective structures inherited from the organization's past.

Ral's teleo-affective structure was not brand new but rather made from its organization's cultural legacy. Ral's teleo-affective structure can be characterized by strong delineation of professions and a strict hierarchy between operational staff and decision-makers. Practical and general understandings of resilience drew on an ideal of collegiality and empowerment of the CMTs. However, the overall teleo-affective structure of the organization from which Ral was created played an ambivalent role in the emergence and establishment of resilience as a practice within Ral. According to the CMTs' general understanding of resilience, work was collegial, iterative and involved trial-and-error. However, CMT members eventually aligned with Ral's formal and strict hierarchy, as suggested in both interviews and observations. In a nutshell, the CMT members had past experience either in safety or commercial activity. While CMTs' own understanding drew on a spirit of fraternity within teams, the teleoaffective structure of Ral implied a strong legacy of hierarchy. These two sets of beliefs and values contradicted each other, generating frustration within the teams regarding the right place for collegiality in resilience practice, as well as the correct basis for their identity. At certain pointsespecially when the legitimacy of CMTs within Ral was questioned-some members of CMTs struggled to figure out their professional identity as either CMTs members or as safety or CRM specialist. These struggles impeded-and sometimes endangered-CMT cohesion.

In Fed, practical understanding, general understanding and action all contributed to generating positive emotions between practitioners with respect to collaboration. However, the teleo-affective structure of Fed hardly supported such practice because of Fed's legacy in terms of identity, culture and professional background. Fed's teleo-affective structure was even called into question by the evolution of the legal framework of emergency management at the national level in France. Legal guidelines released in 1996 and 2004 were consistent with Fed's general 
understanding of resilience and outlined the necessity for organizations to develop transverse capabilities, risk policy and procedures to handle rare but disrupting events. In spite of national and local incentives for transformation, Fed's agents' mindset remained strongly influenced by its teleo-affective structure that comprised values such as hierarchy and a siloed approach to resilience. For instance, Fed's firefighters tended towards a firefighting approach to an incident, while Fed's members who had a background as police officers tended to see events from their own professional perspective. Such teleo-affective structures had a strong impact on action. In critical situations, Fed's members still tended to reflect these siloes and lacked the training and preparation to shift to a transversal approach to resilience. Fed agents led their counterparts from other organizations to adopt a systemic, transversal view on events. But in failing to share this conception, they became frustrated when they realized that their counterparts (or even some colleagues in Fed) were remaining stuck in a silo mentality.

The findings of this chapter open the black box of the interplay between action and structure that lies at the core of resilience practice. They first reveal the complexity of this interplay, which can be both synergic and contradictory. More specifically, they outline that the general understanding of resilience, to some extent, shapes resilience action. Moreover, practical understanding plays an important role in resilience practice consistency by interlinking action to general understanding. However, action can also shape practical understanding, thereby inducing inconsistencies within the structure of resilience practice. Action and its contingency can also come to be at odds with rules. Finally, structure is not always consistent. The components of structure can contradict each other with the teleo-affective on one side and understanding on the other. The following tables sum up the findings. Table 5.3 provides a summary of the common evolution of the interplay between resilience action and resilience structures. Figure 5.2 (at the beginning of the chapter) shows the interplay between resilience practice, structure and action. Finally, Table 5.4 provides a comparative view on the evolution of the structures of resilience practice for Ral and Fed.

As shown in Table 5.4, while Ral and Fed promoted seemingly opposite approaches to resilience, but both faced contradictions between teleo-affective structures and resilience understanding. 
Table 5.3 Overview of the interplay between resilience structure and resilience action

\begin{tabular}{|c|c|c|}
\hline $\begin{array}{l}\text { Structure of resilience as a } \\
\text { practice }\end{array}$ & Definition & Interplay with action \\
\hline General understanding & $\begin{array}{l}\text { Broad understanding of } \\
\text { resilience, covers } \\
\text { frameworks, overall vision } \\
\text { and rationale }\end{array}$ & $\begin{array}{l}\text { Shaped action and } \\
\text { federated agents }\end{array}$ \\
\hline Practical understanding & $\begin{array}{l}\text { Knowing of what to do in a } \\
\text { specific setting }\end{array}$ & $\begin{array}{l}\text { Shaped action but was also } \\
\text { modified by action, at the } \\
\text { expense of general } \\
\text { understanding/practical } \\
\text { understanding/action } \\
\text { alignment }\end{array}$ \\
\hline Rules & $\begin{array}{l}\text { Normative definition of } \\
\text { action }\end{array}$ & $\begin{array}{l}\text { Went in contradiction with } \\
\text { the flow of resilience } \\
\text { action }\end{array}$ \\
\hline Teleo-affective structure & $\begin{array}{l}\text { Set of emotions, intentions } \\
\text { and cultural grounds that } \\
\text { predefine what is acceptable } \\
\text { or not }\end{array}$ & $\begin{array}{l}\text { Contradicted resilience } \\
\text { general understanding }\end{array}$ \\
\hline
\end{tabular}

\section{DISCUSSION}

Ral and Fed represent two different organizations, both characterized by the emergence of divergences between resilience action and an exante organizational framework. Rad had elaborated an expert-oriented vision of resilience, embodied by newly created CMTs. But progressively, the capabilities developed by the CMTs diffused throughout the organization. Conversely, Fed had planned the transversal management of resilience, which confronted the persistence of the siloed distribution of tasks. From this perspective, Ral and Fed failed to impose their initial vision of resilience in the long run. The findings of this chapter outline how arrangements within resilience practice (specifically between action and structure) eventually led these organizations to deviate from their resilience vision and frameworks. No matter how compliant or innovative their vision of resilience was, in the end, the organizations both experienced some contradictions between framed and enacted resilience. This resulted in conflicts, discomfort, motivation collapse, and productivity loss. To nuance our view, resilience in practice was not strictly contradictory. Rather, structure and action mutually influenced each other, 
Table 5.4 Synthesis of findings

\begin{tabular}{|c|c|c|c|c|}
\hline Case & $\begin{array}{l}\text { General } \\
\text { understanding }\end{array}$ & $\begin{array}{l}\text { Practical } \\
\text { understanding }\end{array}$ & Rules & $\begin{array}{l}\text { Teleo-affective } \\
\text { structures }\end{array}$ \\
\hline Ral & $\begin{array}{l}\text { Specific skills and } \\
\text { know-how within } \\
\text { the CMTs. } \\
\text { Diffusion of skills } \\
\text { across professional } \\
\text { types within the } \\
\text { teams }\end{array}$ & $\begin{array}{l}\text { Specific } \\
\text { know-hows of } \\
\text { mass evacuation } \\
\text { and management } \\
\text { of stressed } \\
\text { passengers. } \\
\text { Implied the need } \\
\text { for exemplarity, } \\
\text { which eventually } \\
\text { promoted the } \\
\text { leaking of the } \\
\text { CMT's practical } \\
\text { understanding }\end{array}$ & $\begin{array}{l}\text { The rules initially } \\
\text { internally and } \\
\text { collegially designed } \\
\text { within the service. } \\
\text { However, the } \\
\text { actors progressively } \\
\text { lost the } \\
\text { prerogative of } \\
\text { self-defining } \\
\text { resilience rules in } \\
\text { the course of } \\
\text { action. Growing } \\
\text { inconsistencies } \\
\text { between action } \\
\text { and rules }\end{array}$ & $\begin{array}{l}\text { Affective ties to } \\
\text { the CMTs' } \\
\text { belonging and } \\
\text { identity. Promoted } \\
\text { values and rituals } \\
\text { towards } \\
\text { collegiality. } \\
\text { Contradicted Ral's } \\
\text { teleo-affective } \\
\text { structure that } \\
\text { included a strong } \\
\text { sense of hierarchy }\end{array}$ \\
\hline Fed & $\begin{array}{l}\text { Resilience is an } \\
\text { important matter } \\
\text { for everyone and } \\
\text { requires } \\
\text { orchestration of } \\
\text { distributed skills } \\
\text { and information }\end{array}$ & $\begin{array}{l}\text { How to share } \\
\text { common } \\
\text { knowledge on } \\
\text { incidents and } \\
\text { incident response, } \\
\text { how to } \\
\text { collaborate, } \\
\text { transmit } \\
\text { information, } \\
\text { distribute } \\
\text { responsibilities and } \\
\text { rely on partners' } \\
\text { capacity to develop } \\
\text { and implement } \\
\text { their inner } \\
\text { protocols in case } \\
\text { of need }\end{array}$ & $\begin{array}{l}\text { Rules were defined } \\
\text { in a top-down } \\
\text { fashion. } \\
\text { Parcimonious } \\
\text { definition of rules } \\
\text { in order to leave } \\
\text { room for actors' } \\
\text { autonomy in the } \\
\text { development of } \\
\text { resilience capacities } \\
\text { and processes. } \\
\text { Rules could not be } \\
\text { implemented in } \\
\text { the course of } \\
\text { action }\end{array}$ & $\begin{array}{l}\text { New and positive } \\
\text { emotions } \\
\text { associated to } \\
\text { collaboration. } \\
\text { Importance of } \\
\text { one's expertise as } \\
\text { a source of } \\
\text { legitimacy }\end{array}$ \\
\hline
\end{tabular}

which led to practice evolution. The comparative design of this study outlines how such contradiction is not inherent to one approach specifically (either expert-oriented or transverse) but rather stems from the articulation between the organizational framing of resilience and resilience in action.

Looking more deeply at the two cases under investigation, this chapter outlines three major points. First, the articulation between resilience 
structure and action is evolutionary. Second, the nature of this articulation is complex. Third, the articulation between the structure and action underlying resilience practice depends on the role played by resilience proponents. We detail each of these points here, and, based on this discussion, conclude the chapter by providing practical recommendations for organizations.

First, the results highlight that the relationship between resilience structure (including rules, beliefs, visions and frameworks) and resilience action is not static but rather evolutionary. In both Ral and Fed, the initial framework of resilience manifested through evolving practice. Resilience action initially aligned with practical understanding. The spur to action (such as projects and concrete initiatives) also aligned with resilience understanding. As highlighted by our findings, general understanding and practical understanding both represent important drivers for the translation of a vision of resilience into practice. That said, contradictions eventually emerged between practical understanding and action or between rules and action. Both Ral and Fed eventually confronted patterns of action that were dissonant with their practical understanding of resilience. From this stance, the chapter echoes existing research that has highlighted the dynamic dimension of resilience (Limnios et al., 2014). Future avenues to improve our work would consist of drawing a process view of the interplay between action and structure that composes resilience in practice. By doing so, we could more precisely chart the evolution of resilience as practice.

Second, this chapter allows a nuanced understanding of the seeming contradiction between resilience as framed and resilience as operated. Previous literature has documented the emergence of gaps between conception and practices (Wong-Parodi et al., 2015). At first glance, the contradictions that seemingly characterize Ral and Fed could lead to the inaccurate conclusion that however resilience is conceived, organizations shape actual resilience through action primarily. In line with other chapters in this volume, this chapter suggests that the management of ex-ante resilience is more complex. Examining more deeply the cases, we learnt that organizations can initiate innovative avenues for organizational resilience based on both action and structure. This means that resilience practice simultaneously bears synergies and contradictions that, in our view, have to be managed to grant a return on investment. For instance, the evolution of Ral and Fed reveals how the relative inertia of the teleo-affective structure-at least in relation to resilience-in an 
organization can be at odds with resilience understanding. Such findings are not surprising and echo previous depictions of teleo-affective structures as invisible but powerful (Iedema et al., 2006). The teleoaffective structure does not only bear the values, ideals, emotions and myths associated with resilience. It also comprises organizational memory, past structures, values, emotions and interaction patterns. Despite the innovation and relevance of a plan for resilience, organizational legacy and structures participate in the framing of practical understanding, general understanding and rules. For instance, Fed was previously designed in a siloed fashion to manage incidents and crises. Despite its intention to approach resilience as a transversal matter, it remained strongly influenced by the existing structures that it had previously developed that matched with the silo-oriented view. More than that, siloed expertise proved to be particularly helpful to Fed, confronting tensions resulting from the gap between the formal definition of roles and the actual sources of knowledge.

Third, both in Ral and Fed, resilience was initiated by proponents of resilience who not only found practical opportunities to promote general and practical understanding of resilience; as well, these persons translated a specific vision into concrete action. Their presence and interactions contributed to the fueling of positive emotions and affective ties, which could contribute to an evolution of the teleo-affective structure (Schatzki, 2006). By contrast, the turnover of people who initiated resilience vision significantly impeded its implementation, in particular as organizations could not deal with contradictions between rules and action or teleoaffective structure. From this perspective, the agency of proponents of resilience seems to represent either a strong inhibitor or a strong driver to resilience implementation and is therefore worth examining. To that extent, the findings of this chapter converge with previous literature on the importance of human agency, as well as the importance of institutional work in relation to resilience (Barin Cruz et al., 2016), and the influence of institutional entrepreneurs in organizational contexts characterized by strong institutional pressure (Battilana, 2006). Putting the cases of Ral and Fed into perspective through this literature, one can infer that resilience proponents correspond to crucial drivers for the promotion of resilience practice (in particular when teleo-affective structure impedes the shaping of action from resilience understanding and rules). From the findings of this chapter, one could assume that resilience proponents, through their contribution to institutional work on resilience, promote 
resilience practice consistency overtime. Additional research is necessary to infer, refine and nuance such assumption. From this perspective, we need to better understand the role of proponents' agency in addressing contradictions between understanding and teleo-affective structure. Data analysed for this chapter does not provide enough detail on this specific point and, to that extent, we recommend additional investigation of the role of proponents in resilience practice.

How can organizations address inconsistencies between resilience structure and action? We identify two practical avenues for organizations to handle these inconsistencies. We first propose that organizations develop awareness of their teleo-affective structure-comprising organizational legacy and past experience-when desiging resilience. Through organizational diagnosis, organizations can scan their own teleo-affective structures before initiating transformation (reorganization, creation of processes, teams, structures, etc.). In addition, organizations can reflect on ways to transform their teleo-affective structure to reduce resilience practice inconsistencies. The findings of the chapter suggest that time is important: by the time organizations had framed resilience understanding, they had developed scant awareness of their teleo-affective structure. As a sequential organizational diagnosis seems tricky to implement, we propose that the 'reflection in action' perspective on resilience (Yanow \& Tsoukas, 2009) could help raise awareness of the inherent inconsistencies of resilience practice. Second, we recommend that organizations fully consider the possibility of supporting resilience proponents from an institutional perspective. In terms of policy and frameworks, the findings of this chapter suggest that dedicated recommendations regarding resilience proponents could be enriched and refined. By doing so, organizations would support institutional work on resilience, in particular by empowering resilience proponents in their narratives. They would also support the production of general and practical understanding, which represents the second avenue to maintaining consistency between action and structure of resilience practice over time. Going further, we suggest that frameworks and policies provide enough room for human agency to avoid the rise of inconsistencies between resilience structure and action.

\section{REFERENCES}

Adrot, A., \& Garreau, L. (2010). Interagir pour improviser en situation de crise. Le cas de la canicule de 2003. Revue Française de Gestion, 36(203), 119-131. 
Barin Cruz, L., Aguilar Delgado, N., Leca, B., \& Gond, J.-P. (2016). Institutional resilience in extreme operating environments: The role of institutional work. Business \& Society, 55(7), 970-1016.

Battilana, J. (2006). Agency and institutions: The enabling role of individuals' social position. Organization, 13(5), 653-676.

Benson, J. K. (1977). Organizations: A dialectical view. Administrative Science Quarterly, 22(1), 1.

Boin, A., \& Van Eeten, M. J. (2013). The resilient organization. Public Management Review, 15(3), 429-445.

Djalante, R., \& Lassa, S. (2019). Governing complexities and its implication on the Sendai framework for disaster risk reduction priority 2 on governance. Progress in Disaster Science, 2, 100010.

Duit, A. (2016). Resilience thinking: Lessons for public administration. Public Administration, 94(2), 364-380.

Hale, A., \& Borys, D. (2013). Working to rule or working safely? Part 2: The management of safety rules and procedures. Safety Science, 55, 222-231.

Iedema, R., Rhodes, C., \& Scheeres, H. (2006). Surveillance, resistance, observance: Exploring the teleo-affective volatility of workplace interaction. Organization Studies, 27(8), 1111-1130.

Limnios, E. A. M., Mazzarol, T., Ghadouani, A., \& Schilizzi, S. G. (2014). The resilience architecture framework: Four organizational archetypes. European Management Journal, 32(1), 104-116.

Lindberg, O., \& Rantatalo, O. (2015). Competence in professional practice: A practice theory analysis of police and doctors. Human Relations, 68(4), 561-582.

Lovins, A. B., \& Lovins, L. H. (1982). Brittle power: Energy strategy for national security. Brick House Publishing Company.

Manyena, S. B. (2006). The concept of resilience revisited. Disasters, 30(4), 434450 .

Moynihan, D. P. (2012). A theory of culture-switching: Leadership and red-tape during hurricane Katrina. Public Administration, 90(4), 851-868.

Perrow, C. (2006). Disasters ever more? Reducing U.S. vulnerabilities. In H. Rodriguez, E. L. Quarantelli, \& R. Dynes (Eds.), Handbook of disaster research (pp. 42-54). Springer.

Pettersen, K. A., \& Schulman, P. R. (2019). Drift, adaptation, resilience and reliability: Toward an empirical clarification. Safety Science, 117, 460-468.

Putnam, R. D. (2000). Bowling alone: America's declining social capital. In L. Crothers \& C. Lockhart (Eds.), Culture and politics (pp. 223-234). Springer.

Reynaud, J.-D. (1989). Les règles du jeu. L'action collective et la régulation sociale, 2, 270. Armand Colin.

Schatzki, T. (1996). Social practices: A Wittgensteinian approach to buman activity and the social. Cambridge University Press. 
Schatzki, T. (2002). The site of the social: A philosophical account of the constitution of social life and change. Penn State Press.

Schatzki, T. (2006). On organizations as they happen. Organization Studies, 27(12), 1863-1873.

Schatzki, T., Knorr-Cetina, K., \& Von Savigny, E. (2001). The practice turn in contemporary theory (Vol. 44). Routledge.

Schatzki, T. R. (2012). A primer on practices: Theory and research. In J. Higgs, R. Barnett, S. Billett, M. Hutchings \& F. Trede (Eds.), Practice-based education: Perspectives and strategies (pp. 13-26). Brill Sense.

Schulman, P. R. (1993). The negotiated order of organizational reliability. Administration \& Society, 25(3), 353-372.

Shrivastava, P. (1987). Bhopal: Anatomy of a crisis. Paul Chapman Publishing.

Suchman, L. (2007). Human-machine reconfigurations: Plans and situated action. Cambridge University Press.

Vogus, T. J., \& Sutcliffe, K. M. Organizational resilience: Towards a theory and research agenda. 2007 IEEE International Conference on Systems, Man and Cybernetics, 2007 (pp. 3418-3422). IEEE.

Walls, J. L., \& Hoffman, A. J. (2013). Exceptional boards: Environmental experience and positive deviance from institutional norms. Journal of Organizational Behavior, 34(2), 253-271.

Wiig, S., \& Fahlbruch, B. (2019). Exploring resilience: A scientific journey from practice to theory. Springer.

Wildavsky, A. B. (1988). Searching for safety, 10. Transaction publishers.

Wong-Parodi, G., Fischhoff, B., \& Strauss, B. (2015). Resilience vs. adaptation: Framing and action. Climate Risk Management, 10, 1-7.

Yanow, D., \& Tsoukas, H. (2009). What is reflection-in-action? A phenomenological account. The Journal of Management Studies, 46(8), 1339-1364. 
Open Access This chapter is licensed under the terms of the Creative Commons Attribution 4.0 International License (http://creativecommons.org/licenses/ by $/ 4.0 /$ ), which permits use, sharing, adaptation, distribution and reproduction in any medium or format, as long as you give appropriate credit to the original author(s) and the source, provide a link to the Creative Commons license and indicate if changes were made.

The images or other third party material in this chapter are included in the chapter's Creative Commons license, unless indicated otherwise in a credit line to the material. If material is not included in the chapter's Creative Commons license and your intended use is not permitted by statutory regulation or exceeds the permitted use, you will need to obtain permission directly from the copyright holder.

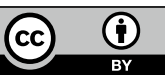

